\title{
Data protection
}

\section{Swedish research under wraps \\ Stockholm}

SwEDEN's Data Inspectorate has caused consternation among sociological researchers by ordering the removal of all personal identification from the records of a research project run by the Institute of Sociology at the University of Stockholm, and completed at the end of last year. The project, known as Metropolit, consisted of the longitudinal study of 15,000 people born in Stockholm in 1952, and had cost Skr7 million (roughly $£ 700,000$ ) over two decades. The university has until 1 May to comply with the inspectorate's ruling.

One consequence of the ruling will be that sociologists will not be able to add to the data now on file, either now or in the future. Indeed, even the potential value of the data so far gathered for control purposes is threatened by the mounting demand, which Swedish liberal newspapers are supporting, that the files should be scrapped completely.

This development may compromise the needs of sociologists and medical researchers elsewhere in Europe for access to the individual records of research projects. In the late 1970 s, an attempt to win government approval for such access, accompanied by assurances of confidentiality, was mounted within the framework of the European Science Foundation, but not in the end pursued.

This turn of events is also an interesting pointer to the changed attitude of Swedish society towards the collection of confidential data about individuals. In 1966, Dr Carl Gunnar Jansson, the head of the Metropolit project, was able to recruit members of his study cohort by distributing study forms to teenagers in school classrooms; social surveys were a routine part of Swedish life in which openness was considered an unavoidable virtue.

At the outset of the project, the teenagers in the sample were told in general terms of the objectives. No direct approach was made to their parents, but Jansson says that there was enough information in the general press for them to know the project's aims. To the information provided by the members of the sample were added data on educational attainment, physical and mental health and infringements of the law derived from government records themselves regarded, in 1966, as "open".

Iansson's problems began only in the mid-1970s, with mounting public concern about the confidentiality of data stored in computers. Although the Swedish Data Protection Act, which came into effect in 1974 , allowed existing research projects to continue, Jansson was told in 1976 that no further data could be added to the files without the informed consent of the sub- jects, then in their twenties. Until the Data Inspectorate reversed that ruling in 1978 , the result was a two-year hiatus in the addition of data to the files, on the grounds that consent would surely be withheld by those in the 15,000 -strong cohort with criminal or other unflattering records, so biasing the sample.

Although Metropolit has now formally ended, Jansson had sought to make the files accessible to future researchers by depositing a key to the identity of the members of the sample in the national archives. Opposition to this proposal was stimulated by an enterprising journalist of Dagens Nyheter (which, ironically, was a strong supporter of the survey when it began). The result has been a general outcry against "Big Brother": 5,000 of the original sample of 15,000 have either asked that their names be withdrawn or that they should have access to their records.

The university will have three weeks in which to appeal against the new ruling once it has been promulgated officially next month, but Jansson, now lecturing in the United States, is unsure whether he will follow this course for fear that an appeal would subject the Metropolit researchers (of whom his wife is one) to further stress. The appearances suggest that the Data Inspectorate will extend the basis of its new ruling to other projects, having also ruled that personal identification should be removed from a follow-up study of women who have had abortions.

Meanwhile, Swedish researchers needing to compile files of personal information may be tempted to follow what is called the "Evajo" option, named after Eva Johansson who, in the mid-1970s, carried out a study of the development and social adaptation of the children of former juvenile delinquents. Considering it unethical to interview the children for fear of the psychological damage that would be caused, but denied permission by the Data Inspectorate to compile a computer file from government records, she took her study outside the scope of the Data Protection Act by assembling the data manually, on index cards. Vera Rich

\section{Pesticide toxicity}

\section{US Congress acts on compromise}

Washington

LAGGARD federal safety testing of pesticides will be given an $\$ 80$ million boost from industry user fees, but also a strict new timetable, if Congress passes legislation put forward by industry and environmental groups. The proposals are meant by both sides in a long-running dispute over pesticide safety to ensure that testing is speeded and that efforts are concentrated on the chemicals of greatest concern.

Many of the 600 or more active ingredients in pesticides registered before 1978 were tested during the 1950 s and 1960 s, when requirements were less demanding. The Federal Insecticide, Fungicide and Rodenticide Act (FIFRA) was amended in 1972 to require the Environmental Protection Agency (EPA) to demand comprehensive industry health and safety studies, but in the intervening fourteen years, only six ingredients have been fully tested and approved; for 475 , even the data needed have not been specified.

Under the amendments to FIFRA now proposed, all the unapproved active ingredients would have to be reregistered according to a strict timetable, with industry paying $\$ 150,000$ to EPA for each material considered. Pesticides previously registered with false or invalid data would be banned. "Special reviews", undertaken when a substance fails a potentially significant toxicity or carcinogenicity test, would be limited to one year's duration; testing of all pesticides on the market would have to be completed in seven years.
Besides the active ingredients, the bill would for the first time require EPA to test thoroughly so-called "inert ingredients", which include all those that do not actually kill the pest but that contain several substances (such as benzene and cadmium compounds) not normally thought of as inert. Because there are 2,000 inert ingredients in use, EPA would each year draw up a priority list of those most in need of more safety data, data which would have to be supplied within four years. The effect of this provision, according to Nancy Drabble of Public Citizen's Congress Watch, would be to put pressure on manufacturers to use those inert ingredients that are most likely to be safe. Other provisions would improve public access to information.

The new compromise has been hammered out over the past year by 41 environmental and consumer groups under the banner of the Campaign for Pesticide Reform and 92 agrichemical companies represented by the National Agricultural Chemicals Association. A bill was introduced in both houses of Congress last week, and given the broad support is thought to have a good chance of passing. But the American Farm Bureau, representing the users of the chemicals, has still not put its name to the bill. It wants to see a clause to protect farmers from lawsuits arising from approved pesticide use, and it has considerable clout in Congress. Negotiations are said to be at a delicate stage.

Tim Beardsley 